\title{
A Motif-Based Analysis to Reveal Local Implied Information in Cross-Shareholding Networks
}

\author{
Qian Liu, ${ }^{1,2}$ Huajiao Li $\mathbb{D}^{1,2}$ Feng An, ${ }^{1,2}$ Nairong Liu, ${ }^{1,2}$ Qing Guan, ${ }^{1,2}$ Jingjing Jia, ${ }^{1,2}$ \\ and Pengli $\mathrm{An}^{1,2}$ \\ ${ }^{1}$ China University of Geosciences, Beijing 100083, China \\ ${ }^{2}$ Key Laboratory of Carrying Capacity Assessment for Resource and Environment, Ministry of Land and Resources, \\ Beijing 100083, China
}

Correspondence should be addressed to Huajiao Li; babyproud@126.com

Received 28 May 2018; Revised 31 August 2018; Accepted 25 September 2018; Published 2 December 2018

Academic Editor: Ana Meštrović Copyright ( 2018 Qian Liu et al. This is an open access article distributed under the Creative Commons Attribution License, which
permits unrestricted use, distribution, and reproduction in any medium, provided the original work is properly cited.

\begin{abstract}
Cross-shareholding is a new type of strategic means for capital operation and is an important component of corporate governance. With the increasing complexity of business motivation, the structure of a cross-shareholding network (CSN) is becoming more intricate, and it exposes various important local patterns with different economic functions. The goal of this paper is to uncover investment mechanisms and economic functions implied in cross-shareholding networks (CSNs) by analyzing the local characteristic patterns of company interactions. In this paper, we construct the CSNs of listed companies and extract the directed triadic motifs to reveal the evolutionary characteristics of local investment patterns at the company and industry levels. On the company level, we find that companies tend to form V-shaped structures with other companies, but bidirectional shareholding patterns and circular relationships in the triads are scarce. On the industry level, we identify the characteristic linking patterns of some industries with a role analysis of the industries. Furthermore, we detect the evolutionary characteristics of industry interrelationships in three implied patterns. Such a motif evolution analysis may provide valuable information for investors and supervisory departments that make decisions about investment portfolios and policy. Meanwhile, this study is also helpful for exploring the implied information in other empirical networks.
\end{abstract}

\section{Introduction}

To explore the interactive behaviors among economic agents, many economic systems have been modeled and better understand as complex networks [1-5], particularly crossshareholding networks (CSNs), which are specific architectures that can reflect the risk-resistant capability of corporate and capital markets [6,7]. With the increasing complexity of business motivations (such as capital financing, spread risk, and industrial alliances), the structure of CSNs is becoming much more intricate and exposes various important local patterns with different economic functions. A series of recent studies have provided a thorough understanding of the global and large-scale organizations of CSNs [8-10]. However, the local organization of CSNs is still not fully understood. Because of the neglect of an indirect-holding pattern, which is a typical local structure in crossshareholding relationships, the control of the largest Chinese real estate company, Vanke Co., has been seized by other companies. Therefore, detecting the local interactive patterns among companies (or industries) and unveiling the implied information contained in these patterns are of crucial importance in understanding the complex crossshareholding behaviors more precisely and in providing investment advice and risk warnings for enterprises and market regulators. In this paper, we explore the local implied information in CSNs, which is revealed through a network motif analysis.

Network motifs have attracted attention as tools for depicting the nontrivial structures of the network at the microscopic scale; each network motif performs specific information-processing tasks $[11,12]$ and can be used to 
explore specific behaviors and functions [13]. These motifs are defined as small recurring subgraphs in a complex network [14] and have been widely used to capture the organizational interactions of the specific system, with examples from biology [15-18], ecology [19], sociology [20], and engineering systems [21]. In particular, the application of network motifs has proven to be very effective in exploring the basic interactions among economic agents [22-24]. For example, some studies extend the index of motif analysis to extract the taxonomy of industries between firms [23, 25], and some analyses detect the transaction patterns of the main industry sector in a Japanese trade network [24]. This research confirms that more trade structure characteristics can be revealed by motifs analysis. However, not much is known about the basic investment patterns of listed companies (or industries) in a CSN. In real-world CSNs, there are some opaque activities, such as chain shareholder behaviors [26] (single-output pattern which is shown as pattern 1 in Figure 1), coholding behaviors $[27,28]$ (single-input pattern which is shown as pattern 2 in Figure 1), and indirect shareholding behaviors [29] (three-chain pattern which is shown as pattern 3 in Figure 1) among the companies. These special interaction patterns that are the local structures in the CSNs reflect the crucial investment mechanisms implied in the equity market. Understanding the patterns of these organization interactions is essential if we are to uncover the mechanism and the structure of the equity market. In addition, as we know, the fluctuation of basic interaction relationships among listed companies can influence the stability of the equity market to some extent $[30,31]$. As a result, we provide a detailed quantitative analysis of the motifs to discover the evolution feature in cross-shareholding relationships.

In this paper, we systematically study evolutionary triadic motifs in CSNs on the micro and macro levels, revealing the implied investment information among companies and industries. We choose Chinese listed companies as our empirical subjects, with a 10 -year evolution period from 2007 to 2016. On the microcosmic aspect, we measure the distributions of motifs in the CSNs for 10 years to explore the fluctuation of the basic investment patterns among the listed companies. On the macroscopic level, we explore the topological characteristics of industry subgraphs. First, we classify the role of nodes in motifs and measure the appearances of these roles in different industry sectors to investigate the primary investment patterns of industries and their evolution. Furthermore, we analyze the interactive characteristics among industries in special motifs to unveil implied investment mechanisms between industries. Thereby, we demonstrate that the anatomy of the local interaction patterns of companies and industries is a promising method to uncover the function and structure of CSNs and other complex networks.

The remainder of this paper is organized as follows. Section 2 describes the dataset and methods. In Section 3, we investigate the evolutionary features of motifs and roles on the micro aspect (firm-level) and the macro aspect (industry-level). Section 4 summarizes our main findings.

\section{Data and Methods}

2.1. Dataset. The source of our data is the RESSET Financial Research Database (http://www.resset.cn/), which is a professional platform that provides various statistical data from Chinese economic markets. The selected documents include annual announcements of the Main Stockholders Lists and Ownership Structure and the CSRC Industry Classification List of all listed companies in the Shanghai stock exchange and Shenzhen stock exchange between 2007 and 2016. The data used in this paper were collected on May 7, 2017. The information in the Main Stockholders Lists and Ownership Structure includes the company code, the latest company name, the stock code, the latest stock name, the shareholder list, and the end data. The information in the CSRC Industry Classification List contains the company code, the latest company name, and the industry classification.

To obtain the cross-shareholding relationships between the listed companies, we selected the listed company as the shareholder attribute. For convenience, we deleted the duplicate items and gave each listed company a unique number, following the letter " $\mathrm{V}$ ".

2.2. Network Construction. The network emerges as an important framework to characterize the interrelationships among the listed companies. Based on the ownership data, we conducted an empirical study on the CSN of Chinese listed companies. The listed companies are viewed as the vertices of the networks, and the directed links indicate the investment relationships among the listed companies. Let the graph of $G=(V, E)$ denote the directed unweighted network that consists of the set of vertices $V$ and the set of edges $E$, and $E$ is defined as Formula (1). The annual data form a network; thus, there are 10 CSNs with time series in our model.

$$
E=\left\{\begin{array}{c}
e_{i j}=1, \quad V_{i} \text { is one of the shareholders of } V_{j}, \\
e_{i j}=0, \quad V_{i} \text { is not the shareholder of } V_{j} .
\end{array}\right.
$$

Thus, in the CSNs, there may exist four types of relationships between the listed company $V_{i}$ and $V_{j}$.

(a) $V_{i} \rightarrow V_{j} V_{i}$ is one of the shareholders of $V_{j}$, but $V_{j}$ is not a shareholder of $V_{i}$

(b) $V_{i} \leftarrow V_{j} V_{j}$ is one of the shareholders of $V_{i}$, but $V_{i}$ is not a shareholder of $V_{j}$

(c) $V_{i} \leftrightarrow V_{j} V_{i}$ and $V_{j}$ are shareholders of each other

(d) $V_{i} \leftrightarrow V_{j}$ neither $V_{i}$ and $V_{j}$ are shareholders of each other

2.3. Motifs Analysis of Companies. To extract the essential features and implied information from large empirical networks, we need to analyze the microscale structure. Motifs serve as the basic building blocks of the network and contain important information. Network motifs are defined as 
significantly overrepresented subgraphs than those that would be expected in randomized networks [14], and they perform specific functions in the network. It is therefore important to analyze the local interaction patterns to explore the behaviors and functions of the real-world networks $[32,33]$. For CSNs, to understand the basic investment mechanisms among companies or industries, we choose the directed triadic motifs as a research model. The connections in a directed network are classified into 13 possible interaction patterns with 3-nodes. All the possible interaction patterns are illustrated in Figure 1, and we number each pattern from 1 to 13 . In our study, we measure the motif distribution to understand the investment patterns among the listed companies in the CSNs, and we identify the motifs using the tool FANMOD, as written by Wernicke and Rasche [34].

2.4. Role Analysis of Industries. Based on the above motif patterns, nodes in a pattern share the same role if they belong to an equivalent structure [11]. For example, in the singleoutput pattern (pattern 1 in Figure 1), two output nodes can be permuted without changing the topological structure of the pattern, whereas the input node and any output node cannot be permuted; thus, this pattern has two roles, role 1 and role 2. The three-chain pattern (pattern 3 in Figure 1) has three roles, whereas the clique pattern (pattern 13 in Figure 1) has only one role. The 13 possible interaction patterns have between one and three roles each; thus, the nodes in the different interaction patterns are classified to represent 30 characteristic functional roles, which are numbered in the circles in Figure 1. An individual node can play different roles if it is a member of multiple motifs in the network.

In the trade network, some industry sectors tend to have distinct directionality patterns and to take specific roles [24, $35,36]$. Similarly, to identify whether an individual industry in the CSN forms some characteristic linking patterns, we measure the distribution of roles in the motifs of the industry. In the investment network, industries in different roles perform different tasks and functions. We can understand the characteristics of industries graphically through a role analysis, which cannot be obtained by the general network statistical analysis. The role of an industry can provide meaningful explanations. For example, in pattern 1 , role $\mathrm{R}=1$ represents that a corresponding industry inclined to invest multiple modes, yet an industry in role $\mathrm{R}=2$ describes that it is often used as a component of the portfolio. For pattern 2 , role $\mathrm{R}=3$ represents an industry as a primary investor and investing in partnership with others, then role $\mathrm{R}=4$ depicts the main investee industry. Moreover, pattern 3 describes complete chain investment mode, role $\mathrm{R}=6$ as an intermediate component with a bidirectional link to role $\mathrm{R}=5$ and role $\mathrm{R}=7$.

Here, we keep the connection of the CSN unchanged, and transform the attributes of the nodes to the industries corresponding to the companies, then determine the characteristic linking patterns of an individual industry by counting the distribution of roles in motifs of the industry. Let $G_{\lambda}=\left(V_{\lambda}, E\right)$ represent the subgraph that consists of nodes, with an industry $\lambda$. We calculate the number of roles $R$ that appear in an industry $\lambda$ by Formula (2).

$$
N_{\lambda}^{R}=\sum_{i \in V_{\lambda}} n_{i}^{R}
$$

where $n_{i}^{R}$ represents the number of roles $R$ that appears in node $i$, and $i$ represents each node in the network. To compare the role characteristics in different industries, we normalize $N_{\lambda}^{R}$ by the number of all roles in an industry $\lambda$. The proportion is calculated as follows:

$$
\eta_{\lambda}^{R}=\frac{N_{\lambda}^{R}}{\sum_{R_{j}} N_{\lambda}^{R_{j}}},
$$

where $R_{j}$ represents each of the different roles, and $N_{\lambda}^{R_{j}}$ is the number of roles $R_{j}$ that appears in an industry $\lambda$. Then, we can obtain a Z-score of roles (defined as $\eta_{\lambda}^{R} *$ ) for the motifs [24] by the zero-mean normalizations, which is an index to quantify the role characteristics of industries as follows:

$$
\eta_{\lambda}^{R} *=\frac{\eta_{\lambda}^{R}-\mu\left(\eta_{\lambda}^{R}\right)}{\sigma\left(\eta_{\lambda}^{R}\right)}
$$

where $\mu\left(\eta_{\lambda}^{R}\right)$ and $\sigma\left(\eta_{\lambda}^{R}\right)$ represent the mean and standard deviation of the normalized appearance value of role $R$ in an industry $\lambda$, respectively. A higher value of $\eta_{\lambda}^{R} *$ indicates a high frequency appearance of role $R$ in an industry $\lambda$.

2.5. Implied Relationships among Industries. Through crossshareholding, strategic alliances can be formed among the listed companies in terms of technology, personnel, sales, and innovation for joint cooperation advantages. Most previous research studies of cross-holding focused on the ownership relationships and the capital allocation aspect $[37,38]$, yet there is another important factor of strategic alliance among companies, which is industrial alliance [39]. With industrial alliance, business collaboration and integration among the listed companies can be effectively achieved. Therefore, it is important to investigate not only the roles of individual industries in the CSN but also the implied relationships among industry sectors in different subgraphs.

To investigate the industry interrelation in the CSN, we analyze three special connected pattern bases in the shareholding relationships among industries: the coholding relationships, the chain shareholder relationships, and the indirect shareholding relationships. These three relationships are indirect but frequently observed features in emerging markets and represent distinct economic functions. Previously, some studies borrowed the concept of structural equivalence to research the coholding behavior between shareholders based on the primitive shareholding relationships $[27,28]$. Similarly, some scholars performed the decreasing-mode method to obtain the coattendance behavior of senior executives [26]. In addition, for the CSN, there were numerous studies in the literature using 

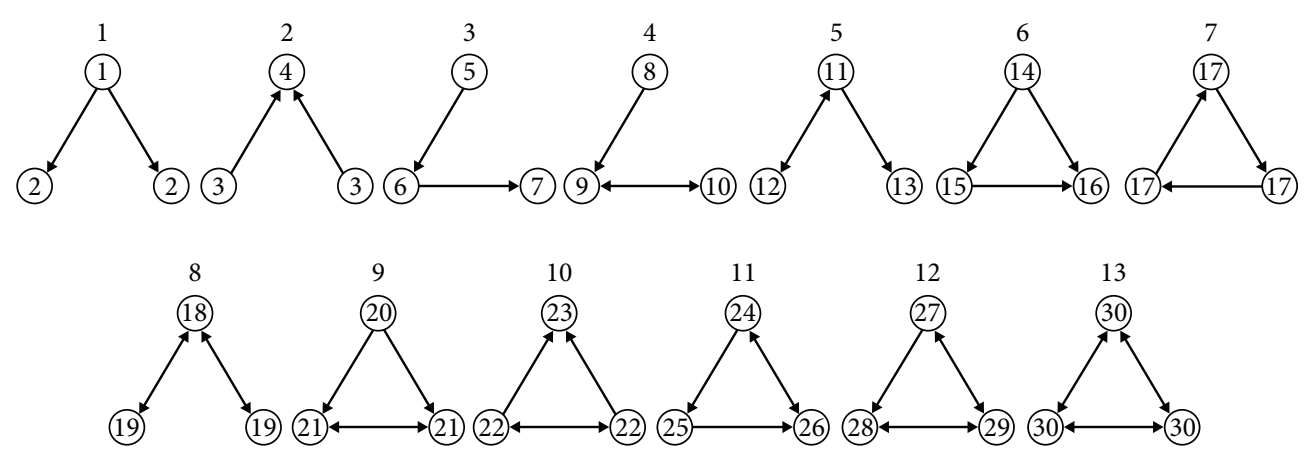

FIgURE 1: All 13 types of interaction triads with 30 characteristic roles.

models based on the Leontief input-output scheme to explore indirect ownership relationships [37, 40-42]. These studies explored the specific interactions of ownership structure with different techniques and scales. However, all the relationships mentioned above (Figure 2) exist as different functions for the CSN of the listed companies, and there is no uniform standard to compare and analyze these implied relationships.

In our study, based on the distribution of industry motifs, we analyze three common relationships in the CSN and reveal the hidden information between industries, which is shown in Figure 2. Pattern 1 denotes the relation between industries (the red nodes) that share a common shareholder; pattern 2 and pattern 3 represent relationships among industries (the green nodes and blue nodes) that invest in the same sector and hold indirect ownership, respectively. We investigate the statistical distribution of the implied relationships between the two nonconnected industries in the motifs through the interactions with intermediaries from 2007 to 2016. As a result, we explore the evolutionary trend of implied relationships among the industries for 10 years. For the equity market, it is useful to help the researcher find the potential relationships among industries for strategic alliances.

\section{Results and Analysis}

As mentioned above, based on the mutual investment relationships among listed companies, we can obtain the CSNs of the Chinese equity market for 10 years, which may include one-sided shareholdings, reciprocal shareholdings, and pyramiding structures. To research the implied information in the CSNs, we analyze the characteristic interaction patterns among the listed companies at the company level and the industry level.

3.1. Analysis at the Company Level. The composition of motifs helps to reveal the basic shareholding patterns among the listed companies. Therefore, to explore the evolutionary trend of triadic motifs in the CSN from 2007 to 2016, we calculate the relative proportion of different motifs in real networks rather than the Z-score [25], since we are not interested in comparing with random

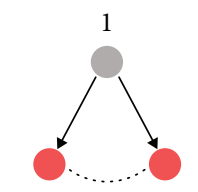

Co-shareholder

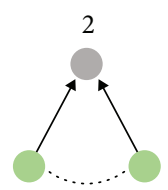

Co-holding

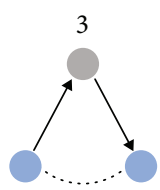

Indirect-holding
FIgURE 2: Three types of implied relationships among industries. Gray nodes represent intermediaries linking two nonconnected industries in triads. Dotted lines depict implied relationships between two nonconnected colored nodes (coshareholder relationship between red nodes in pattern 1, coholding relationship between green nodes in pattern 2 , and indirectholding relationship between blue nodes in pattern 3 ).

groups. Figure 3 shows the motifs' distribution in the CSNs in the last decade.

According to Figure 3, we observe that the CSNs are composed to 6 types of motifs (from motifs 1 to motifs 6 ) over this decade. All the motifs except motif 6 are V-shaped triads. Furthermore, the network is mainly composed of motif 1 , motif 2 , and motif 3. Among these motifs, motif 1 indicates the diversified investment behavior of the listed company, motif 2 represents the common shareholding behavior between the listed companies through information sharing $[22,43]$, and motif 3 reflects the listed companies that have indirect interests in each other. Previously, the distribution of the three main motifs was nearly even. This trend changed after the financial crisis in 2008, when more companies tended to diversify investments to reduce investment risk, and the distribution of the basic investment patterns has been relatively stable over the last five years (motif 1 accounts for approximately half of all motifs; the proportion of motif 2 and motif 3 are approximately $20 \%$ each). However, motif 4 and motif 5 own a bipartite shareholding pattern, which is a universal cross-shareholding behavior between pairs, but they account for a very low proportion of the total motifs in triads (the highest proportions are $2.5 \%$ and $1.88 \%$ in 2016, respectively).

The composition reveals that the cross-shareholding of companies can result in the complex interdependence among the economic entities, and companies tend to form $\mathrm{V}$-shaped 


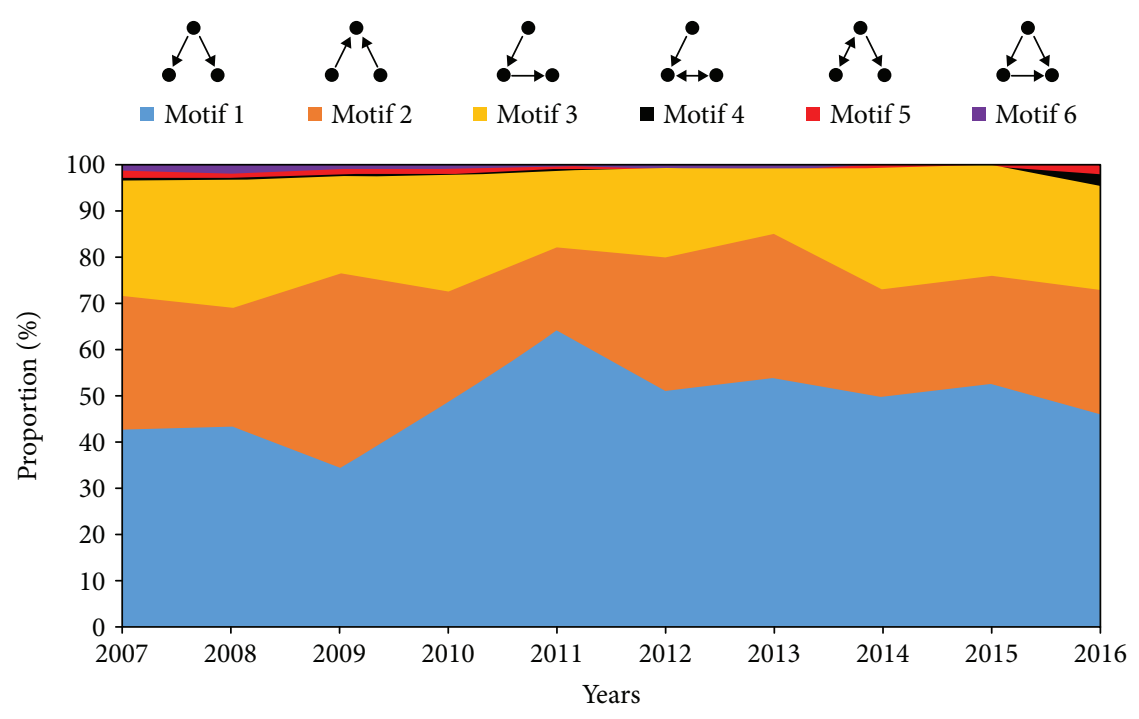

FIgURE 3: The evolution of the distribution of motifs in CSNs.

structures with others, but bidirectional shareholding patterns and the circular relationships of triads are scarce.

3.2. Analysis at the Industry Level. In this section, we analyze the evolutionary characteristics of industry roles and relationships in the CSNs. We select 2007, 2010, 2013, and 2016 as sample years to show the evolutionary characteristics. In addition, to make the presentation of the results more readable and simple, we define the abbreviations for each industrial sector (see Table 1).

3.2.1. The Evolution of Industry Roles. To further analyze the characteristic linking patterns among industries, we convert the attributes of the nodes in the CSNs from a company to an industry. The topology of networks and motif remains constant; we next calculate the investment characteristics of industries. According to the CSRC's industry classification, the companies belong to either of 19 industry sectors. We count the annual distribution of industry sectors in the triadic motifs of the CSNs between 2007 and 2016, which are presented in Table 2 . We can see that nearly $90 \%$ (even $95 \%$ in 2015 and in 2016) of all listed companies belong to either of the top nine industries (first nine industries on the list) in Table 2. Only a small part of the motif consists of nodes that belong to neither of these industries; therefore, in our study, we focus on these nine major industries.

In addition, as shown in Table 2, the number of the industrial distribution changed constantly over the decade, nevertheless the overall patterns stayed stable and nearly all the industries appear in triadic motifs with crossshareholding relationships.

Furthermore, to identify the characteristic linking patterns of individual industries in the triadic motifs, we measure the distribution of roles in the motifs of the industry by the Z-score of the roles, which are calculated by Formulas (2) to (4). The characteristics of each role are presented in Figure 1. With the motifs' distribution presented above, we
TABLE 1: Industrial sectors' abbreviations.

\begin{tabular}{|c|c|}
\hline Abbreviations & Full name of Industrial sectors \\
\hline Agriculture & $\begin{array}{l}\text { Agriculture, forestry, animal husbandry, and } \\
\text { fishery }\end{array}$ \\
\hline Comprehensive & Comprehensive industry \\
\hline Construction & Construction \\
\hline Culture & Culture, sports, and entertainment \\
\hline E\&H power & $\begin{array}{c}\text { Electric power, heat power, gas and water } \\
\text { production, and supply }\end{array}$ \\
\hline Education & Education \\
\hline Finance & Finance \\
\hline H\&S work & Healthcare and social work \\
\hline $\begin{array}{l}\text { Hotels \& } \\
\text { catering }\end{array}$ & Hotels and catering \\
\hline Information & $\begin{array}{c}\text { Information, transmission, computer } \\
\text { services \& software }\end{array}$ \\
\hline Leasing & Leasing and business services \\
\hline Manufacturing & Manufacturing \\
\hline Mining & Mining \\
\hline Public facilities & $\begin{array}{l}\text { Water conservancy, environment, and } \\
\text { public facilities management }\end{array}$ \\
\hline Real estate & Real estate \\
\hline $\begin{array}{l}\text { Resident } \\
\text { services }\end{array}$ & Resident services, repair, and other services \\
\hline S\&T services & Scientific and technological services \\
\hline Transport & Transport, storage, and post \\
\hline Wholesale & Wholesale and retail \\
\hline
\end{tabular}

next analyze the role distribution of the industry in the main motifs, which are motif 1 , motif 2 , and motif 3 . Thus, we analyze the appearance of the first seven roles (see 
TABLE 2: Annual distribution of industry sectors in the triadic motifs of the CSNs.

\begin{tabular}{|c|c|c|c|c|c|c|c|c|c|c|}
\hline & 2007 & 2008 & 2009 & 2010 & 2011 & 2012 & 2013 & 2014 & 2015 & 2016 \\
\hline Manufacturing & $39 \%$ & $42 \%$ & $35 \%$ & $39 \%$ & $40 \%$ & $45 \%$ & $41 \%$ & $43 \%$ & $36 \%$ & $39 \%$ \\
\hline E\&H power & $10 \%$ & $10 \%$ & $9 \%$ & $12 \%$ & $11 \%$ & $11 \%$ & $12 \%$ & $10 \%$ & $18 \%$ & $13 \%$ \\
\hline Finance & $5 \%$ & $6 \%$ & $8 \%$ & $9 \%$ & $8 \%$ & $8 \%$ & $10 \%$ & $10 \%$ & $13 \%$ & $13 \%$ \\
\hline Transport & $6 \%$ & $7 \%$ & $7 \%$ & $7 \%$ & $7 \%$ & $5 \%$ & $6 \%$ & $5 \%$ & $9 \%$ & $8 \%$ \\
\hline Wholesale & $15 \%$ & $11 \%$ & $13 \%$ & $12 \%$ & $12 \%$ & $9 \%$ & $10 \%$ & $11 \%$ & $6 \%$ & $8 \%$ \\
\hline Real estate & $10 \%$ & $8 \%$ & $9 \%$ & $6 \%$ & $6 \%$ & $6 \%$ & $5 \%$ & $5 \%$ & $6 \%$ & $8 \%$ \\
\hline Information & $3 \%$ & $3 \%$ & $4 \%$ & $2 \%$ & $2 \%$ & $5 \%$ & $3 \%$ & $3 \%$ & $2 \%$ & $4 \%$ \\
\hline Construction & $2 \%$ & $3 \%$ & $3 \%$ & $4 \%$ & $3 \%$ & $3 \%$ & $5 \%$ & $4 \%$ & $4 \%$ & $3 \%$ \\
\hline Mining & $3 \%$ & $4 \%$ & $3 \%$ & $3 \%$ & $3 \%$ & $2 \%$ & $1 \%$ & $3 \%$ & $2 \%$ & $2 \%$ \\
\hline S\&T services & $1 \%$ & $1 \%$ & $1 \%$ & $1 \%$ & $1 \%$ & $1 \%$ & $0 \%$ & $1 \%$ & $2 \%$ & $0 \%$ \\
\hline Hotels \& catering & $2 \%$ & $2 \%$ & $2 \%$ & $1 \%$ & $2 \%$ & $2 \%$ & $1 \%$ & $2 \%$ & $1 \%$ & $1 \%$ \\
\hline Education & $1 \%$ & $1 \%$ & $1 \%$ & $1 \%$ & $1 \%$ & $1 \%$ & $0 \%$ & $1 \%$ & $1 \%$ & $1 \%$ \\
\hline Culture & $2 \%$ & $1 \%$ & $1 \%$ & $1 \%$ & $1 \%$ & $1 \%$ & $1 \%$ & $1 \%$ & $0 \%$ & $2 \%$ \\
\hline Leasing & $2 \%$ & $1 \%$ & $1 \%$ & $1 \%$ & $1 \%$ & $1 \%$ & $2 \%$ & $1 \%$ & $0 \%$ & $1 \%$ \\
\hline Comprehensive & $2 \%$ & $1 \%$ & $1 \%$ & $1 \%$ & $1 \%$ & $1 \%$ & $1 \%$ & $0 \%$ & $0 \%$ & $0 \%$ \\
\hline H\&S work & $0 \%$ & $0 \%$ & $1 \%$ & $1 \%$ & $1 \%$ & $1 \%$ & $1 \%$ & $1 \%$ & $0 \%$ & $0 \%$ \\
\hline Public facilities & $1 \%$ & $1 \%$ & $0 \%$ & $0 \%$ & $0 \%$ & $0 \%$ & $0 \%$ & $0 \%$ & $0 \%$ & $0 \%$ \\
\hline Agriculture & $0 \%$ & $0 \%$ & $0 \%$ & $0 \%$ & $2 \%$ & $2 \%$ & $1 \%$ & $1 \%$ & $0 \%$ & $0 \%$ \\
\hline Resident services & $0 \%$ & $0 \%$ & $0 \%$ & $0 \%$ & $0 \%$ & $0 \%$ & $0 \%$ & $0 \%$ & $0 \%$ & $0 \%$ \\
\hline
\end{tabular}

Note: The cells with " $0 \%$ " are the industries that did not appear in the triadic motifs.

Figure 1) in the top nine industries. Figure 4 shows the results. Over the decade, we observe that the listed companies in the real estate industry always take the role $\mathrm{R}=1$, which reflects the investment in real estate coming from multiple ways. This result also affirms that Chinese real estate has accumulated massive funds and that it invests in multifields to hedge risk. The listed companies in manufacturing and information (which is short for Information, Transmission, Computer Services \& Software) are more prominent in role $\mathrm{R}=2$, which shows that the corresponding companies have a coshareholder relationships with other partners. This feature indicates that the industry of manufacturing and information is frequently a member in the diversified portfolios of the listed companies. In addition, construction companies occupy roles $\mathrm{R}=1$ and $\mathrm{R}=3$ with output links. However, finance companies are more likely to occupy roles $\mathrm{R}=2$ and $\mathrm{R}=4$ with input links, which indicates that investing in financial companies is always the main channel for the listed companies to achieve indirect financing in the Chinese equity market. The connection patterns in other industries are constantly fluctuating over time.

Based on the above results, we show that the industry distribution of listed companies is relatively concentrated. Additionally, in the Chinese CSN, investment in some industries presents special connection patterns.

3.2.2. The Evolution of the Implied Interactions between Industries. From the above results, the characteristic linking patterns of individual industries have been found. For instance, in motif 1 , we find that companies in both manufacturing and information take the role $\mathrm{R}=2$, whether or not shareholders (who play role $\mathrm{R}=1$ ) tend to invest in these two industries or the same industry at the same time. To explore the interrelation between two nonconnected industries in the motifs, we further detect the evolution of the implied relationships between industries in the special connection patterns, which are presented in Figure 2. Figures 5-7 represent the evolutionary characteristics of the statistical distribution of the implied relationships between the two nonconnected industries in the corresponding motifs. The color of the blocks represents the number of the implied interactions between the corresponding industries, varying from dark blue, when there is no interaction, to light yellow, when they are closely interacted.

At first, we investigate the industries with coshareholder relationships; Figure 5 describes the numbers of coshareholder relationships between industries that take the role $\mathrm{R}=2$ in motif 1 from 2007 to 2016. Interactions between roles $\mathrm{R}=2$ are undirected; thus in Figure 5, we mirror the lower left half of each subplot to upper right. During the decade, we can observe that the distributions are concentrated in the ninth column, which indicates that most companies choose manufacturing and other partners for a diversified portfolio. Among them, companies investing in two manufacturing companies have always been the dominant pattern. After the financial crisis, investing in both manufacturing and finance also became dominant. In addition, in recent years, some companies began to choose the information industry and manufacturing for a portfolio. 

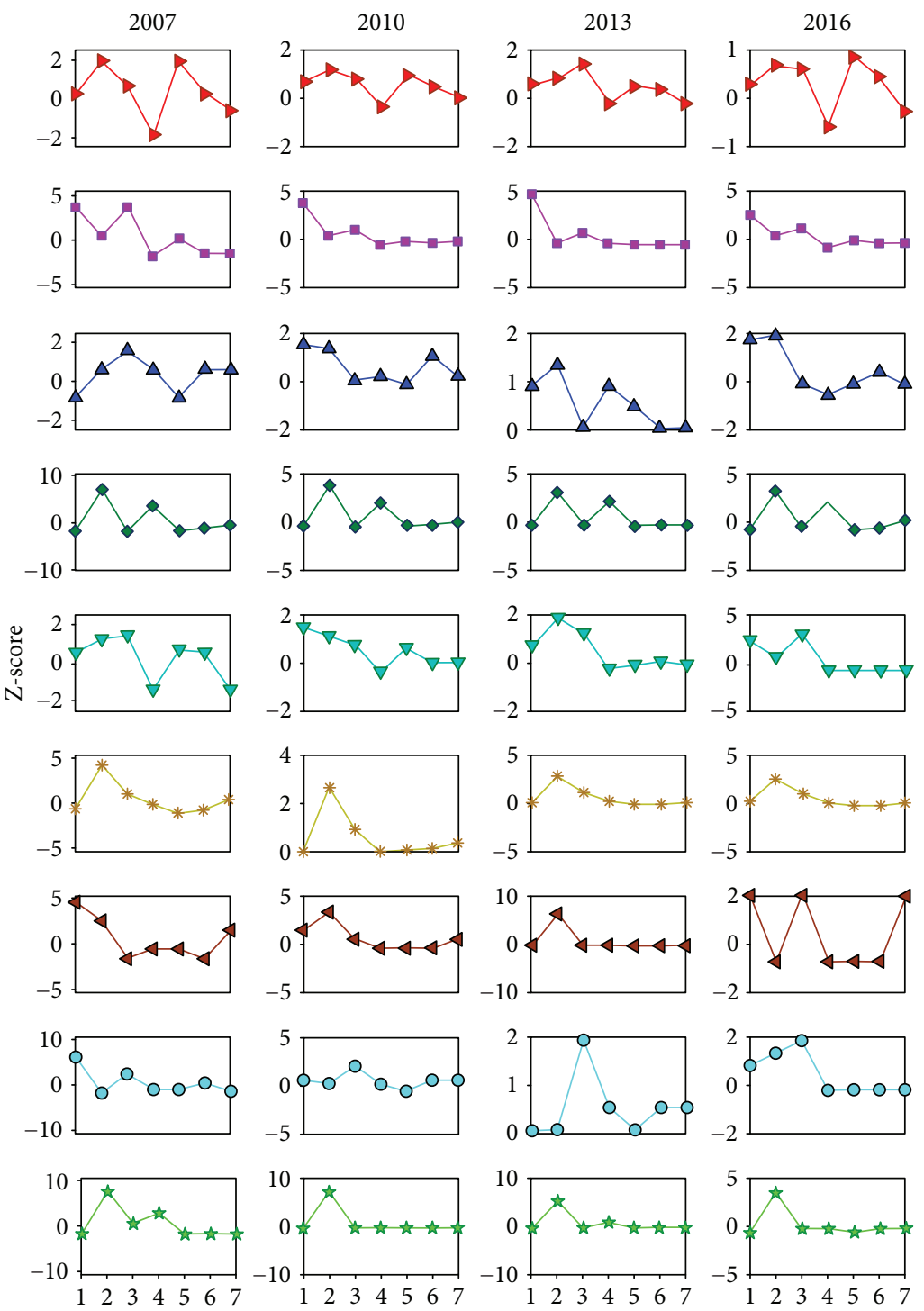

Roles
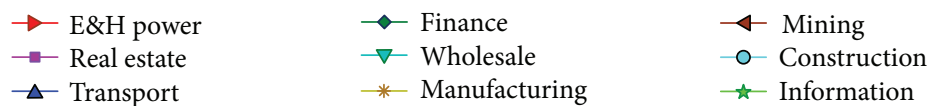

FIGURE 4: The changing tendency of the role distribution in main industries. The abscissas represent different roles; the characteristics of each role are presented in Figure 1.

Secondly, we analyze the evolution characteristics of the coholding relationships between industries that take role $\mathrm{R}=3$ in motif 2, which are shown in Figure 6. Similar to what was mentioned above, interactions between the role $\mathrm{R}=3$ are undirected; the statistics are distributed in the upper right portion of the whole block. Previously, the coholding relationships between companies of manufacturing and real estate accounted for the majority, but that number decreased in recent years, and the coholding relationships between manufacturing and E\&H power (which is short for electric power, heat power, gas and water production, and supply) became much stronger. This trend reflects the fact that with the increasing demand for electricity and energy supplies in recent years, the E\&H power industry and manufacturing industry are creating a synergy to strengthen the construction of power equipment.

At last, we detect the special implied interaction among industries, which is the indirect-holding relationship, taking the roles $R=5$ to role $R=7$ in motif 3 . Figure 7 describes the evolutionary distribution of this relationship. In particular, the interactions are directed; for example, the dark red block in 2007 indicated that companies in the wholesale industry indirectly held companies in manufacturing by investing in the intermediary companies. In the indirect- 

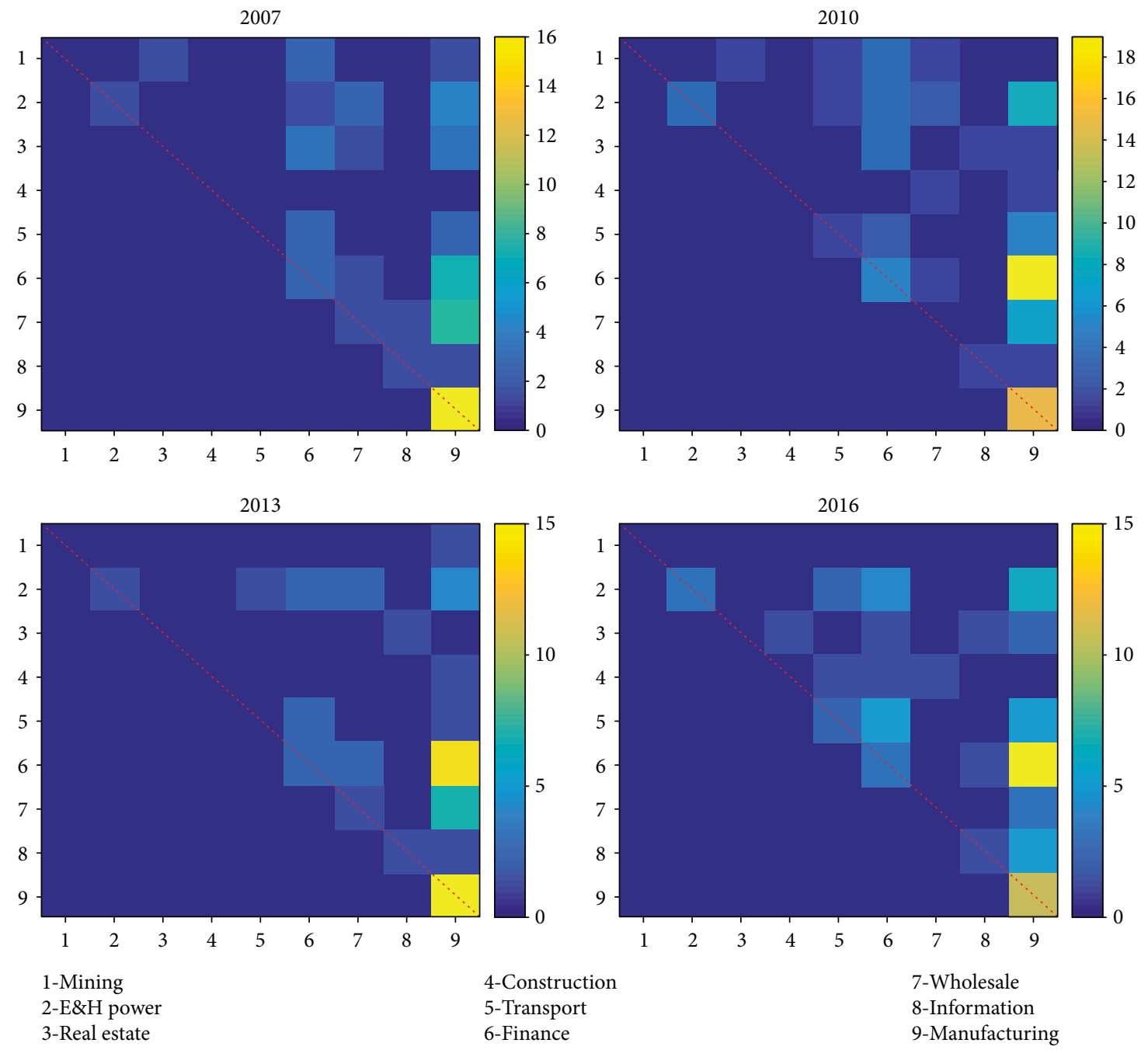

FIgURE 5: The number of coshareholder relationships among industries in motif 1 .

holding relationships, we can observe that the primary companies were mainly from the wholesale industry in 2007, and in recent years that changed to the E\&H power industry; manufacturing is the industry that has the largest number of output links.

From the results above, we can see that the investment strategy and the implied interactions between industries in the cross-shareholding market change with the development and adjustment of the Chinese industrial structure.

\section{Conclusions}

As an important means of capital operation, crossshareholding is a complex economic phenomenon that occurred with the development of listed companies and the evolvement of corporate structure. It is important to study the evolution of the essential structures of crossshareholding behavior to understand the investment mechanisms among the listed companies. In this paper, we construct the CSNs of the listed companies and extract the directed triadic motifs to reveal the evolutionary characteristics of the basic investment patterns at the company and industry levels. By using the motifs analysis, we capture some information that is implied in the local structure of the CSNs. In financial markets, our research can be used to detect underlying relationships of financial entities and identify potential risks in markets such as portfolios. Meanwhile, this method can also be used to explore the implied information in other empirical networks. For example, in international trade network, relevant scholars can investigate the roles of different countries and detect potential trade partners or competitors. The main conclusions are as follows.

First, the cross-shareholding of companies can result in the complex interdependence among the economic entities. The constitution of the motifs reveals that there are multiple shareholding patterns among the Chinese CSNs, particularly in V-shaped triads. Previously, motifs were distributed nearly evenly in three main motifs (motif 1 to motif 3); then, the investment behavior tended to be diversified (coholding behavior is the majority) because 

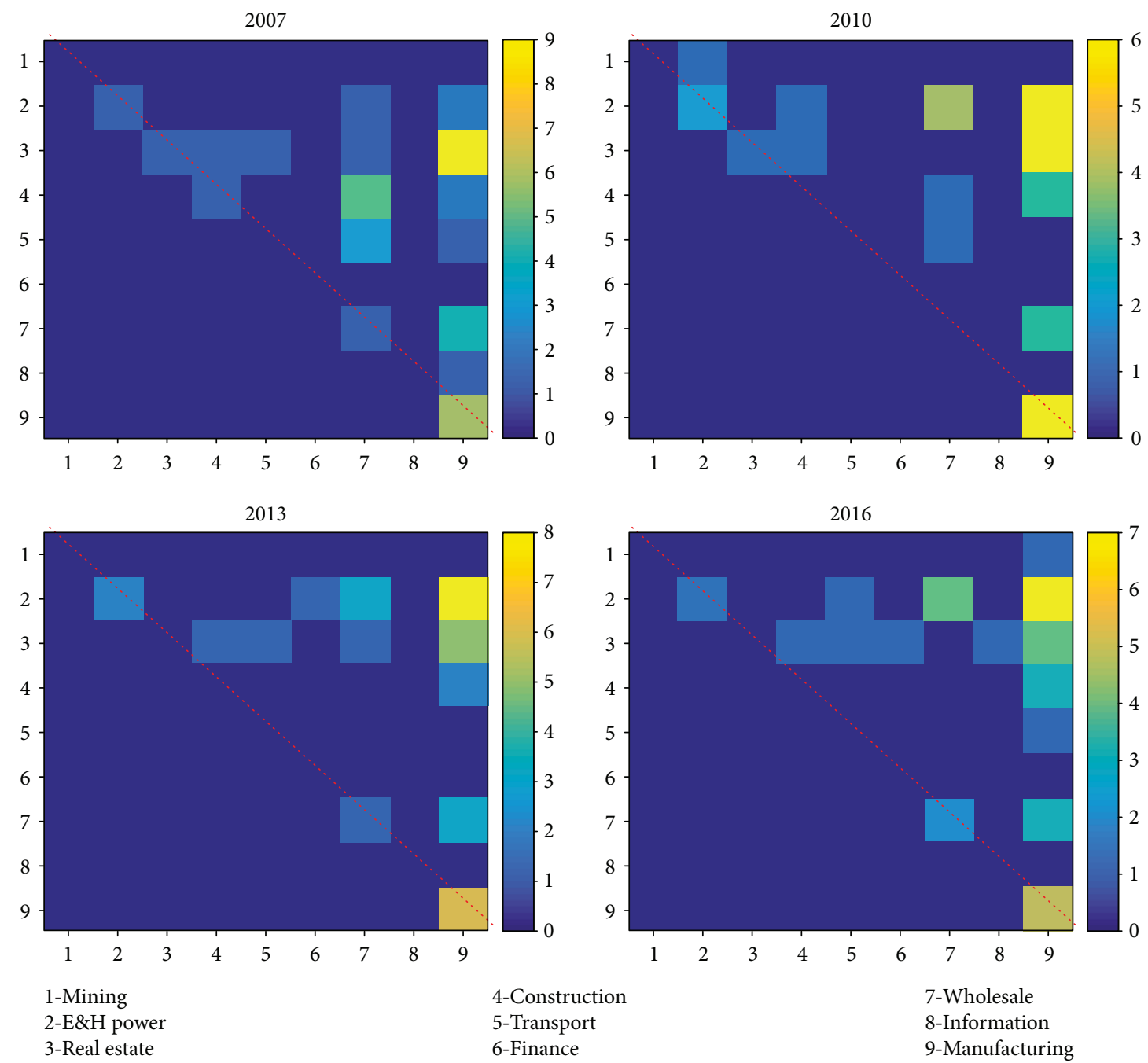

FIGURE 6: The number of coholding relationships among industries in motif 2.

of the global economic crisis, which are also confirmed in the research of coholding networks [28].

Second, the industrial distribution in the triadic motifs of the CSNs is widely but relatively concentrated. In addition, different industries play various roles. Although the investment structure constantly changes, special investment patterns for some industries are still identifiable. Real estate always plays the role of the investor, particularly in investing in multifields, whereas manufacturing and information are frequently members of the diversified portfolios for the listed companies. Finance companies are always the choice for the listed companies to achieve indirect financing. These findings can provide valuable information to equity market researchers and related supervisory departments.

Third, we detected the evolutionary characteristics of industry interrelationships in three different interaction patterns. The performed analysis of coshareholder relationships demonstrated that investing in both the manufacturing and finance industries became predominant after the financial crisis. In addition, with the increasing demand for electricity and energy supplies in the recent years, the coholding relationship between the E\&H power industry and the manufacturing industry increased to strengthen the construction of power equipment.

This paper perform an intensive analysis of triadic motifs in the dynamic CSNs. The empirical analyses may serve to provide an easily interpretable view of the investment behaviors of cross-shareholding listed companies. As a result, our study will be helpful to researchers or investors who are interested in knowing more about investment behaviors (such as investment portfolios).

In this study, we only consider the listed companies as empirical subjects, without considering other economic entities. In the future, we could extend the dataset, or we could research other economic entities with distinctive characteristics, to further systematically and comprehensively explore the hidden information in the equity market. Moreover, it would be an interesting task to investigate motifs with multinode, which may help to discover more special investment 

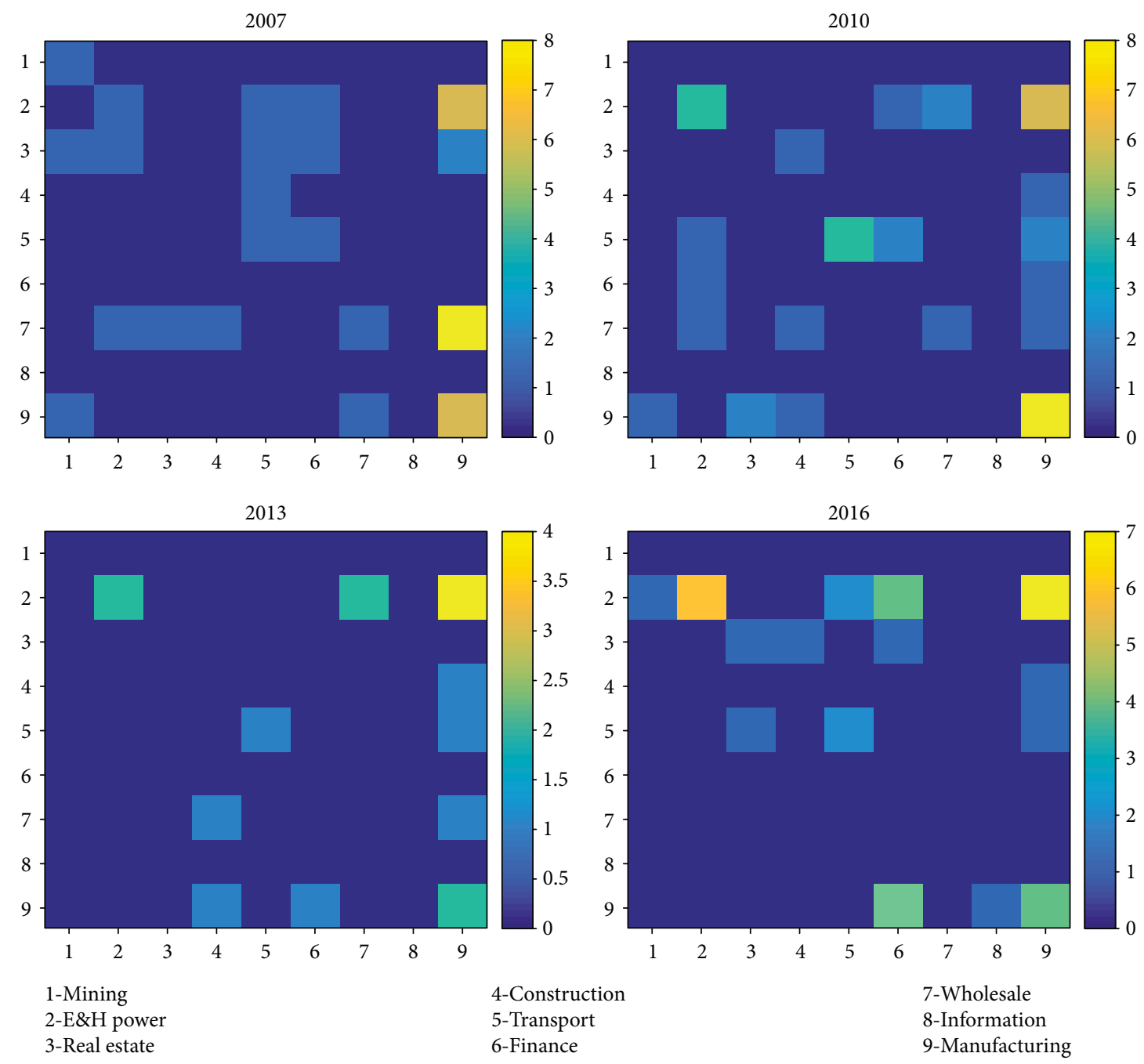

FIgURE 7: The number of indirect-holding relationships among industries in motif 3.

patterns, such as the multichain pattern to explore the underlying investor. Another opportunity for more detailed research is considering the correlations between the different motifs among companies and industries to figure out the underlying evolutionary principles of the CSNs or even universal principles of the equity market. We leave these topics to our future work.

\section{Data Availability}

The cross-shareholding data used to support the findings of this study may be released upon application to the Financial Research Database, who can be contacted from http://www.resset.cn/.

\section{Conflicts of Interest}

The authors declare that they have no conflicts of interest.

\section{Acknowledgments}

This research is supported by grant from the National Natural Science Foundation of China (Grant No. 41701121), the Beijing Youth Talents Funds (2017000020124G190), and the Fundamental Research Funds for the Central Universities (Grant No. 2-9-2017-041). We would like to thank the manufacturer of FANMOD software, which helped obtain statistical results in this paper. In addition, we are grateful to the reviewers for their comments and for helping to prepare the presentation of this manuscript.

\section{References}

[1] F. Schweitzer, G. Fagiolo, D. Sornette, F. Vega-Redondo, A. Vespignani, and D. R. White, "Economic networks: the new challenges," Science, vol. 325, no. 5939, pp. 422-425, 2009.

[2] B. M. Tabak, T. C. Silva, and A. Sensoy, "Financial networks," Complexity, vol. 2018, Article ID 7802590, 2 pages, 2018. 
[3] Q. Liu, H. Li, X. Liu, and M. Jiang, "Information networks in the stock market based on the distance of the multi-attribute dimensions between listed companies," Physica A: Statistical Mechanics and its Applications, vol. 496, pp. 505-513, 2018.

[4] S. Li and S. Wen, "Multiplex networks of the guarantee market: evidence from China," Complexity, vol. 2017, Article ID 9781890, 7 pages, 2017.

[5] L. Rossoni, C. E. Aranha, and W. Mendes-Da-Silva, "The complexity of social capital: the influence of board and ownership interlocks on implied cost of capital in an emerging market," Complexity, vol. 2018, Article ID 6248427, 12 pages, 2018.

[6] D. Cai and Y. Karasawa-Ohtashiro, "International crossownership of firms and strategic privatization policy," Journal of Economics, vol. 116, no. 1, pp. 39-62, 2015.

[7] T. Fischer, "No-arbitrage pricing under systemic risk: accounting for cross-ownership," Mathematical Finance, vol. 24, no. 1, pp. 97-124, 2014.

[8] H. Li, H. An, X. Gao, J. Huang, and Q. Xu, "On the topological properties of the cross-shareholding networks of listed companies in China: taking shareholders' cross-shareholding relationships into account," Physica A: Statistical Mechanics and its Applications, vol. 406, pp. 80-88, 2014.

[9] Y.-y. Ma, X.-t. Zhuang, and L.-x. Li, "Research on the relationships of the domestic mutual investment of China based on the cross-shareholding networks of the listed companies," Physica A: Statistical Mechanics and its Applications, vol. 390, no. 4, pp. 749-759, 2011.

[10] T. Khanna and C. Thomas, "Synchronicity and firm interlocks in an emerging market," Journal of Financial Economics, vol. 92, no. 2, pp. 182-204, 2009.

[11] N. Kashtan, S. Itzkovitz, R. Milo, and U. Alon, “Topological generalizations of network motifs," Physical Review E, vol. 70, no. 3, 2004.

[12] S. Mangan and U. Alon, "Structure and function of the feedforward loop network motif," Proceedings of the National Academy of Sciences of the United States of America, vol. 100, no. 21, pp. 11980-11985, 2003.

[13] U. Alon, "Network motifs: theory and experimental approaches," Nature Reviews Genetics, vol. 8, no. 6, pp. 450461, 2007.

[14] R. Milo, S. Shen-Orr, S. Itzkovitz, N. Kashtan, D. Chklovskii, and U. Alon, "Network motifs: simple building blocks of complex networks," Science, vol. 298, no. 5594, pp. 824-827, 2002.

[15] S. S. Shen-Orr, R. Milo, S. Mangan, and U. Alon, "Network motifs in the transcriptional regulation network of Escherichia coli," Nature Genetics, vol. 31, no. 1, pp. 64-68, 2002.

[16] J. Berg and M. Lässig, "Local graph alignment and motif search in biological networks," Proceedings of the National Academy of Sciences of the United States of America, vol. 101, no. 41, pp. 14689-14694, 2004.

[17] O. Sporns and R. Kötter, "Motifs in brain networks," PLoS Biology, vol. 2, no. 11, article e369, 2004.

[18] N. Geard, S. Bullock, R. Lohaus, R. B. R. Azevedo, and J. Wiles, "Developmental motifs reveal complex structure in cell lineages," Complexity, vol. 16, no. 4, 57 pages, 2011.

[19] P. V. Paulau, C. Feenders, and B. Blasius, "Motif analysis in directed ordered networks and applications to food webs," Scientific Reports, vol. 5, no. 1, 2015.

[20] B. Allen, G. Lippner, Y. T. Chen et al., "Evolutionary dynamics on any population structure," Nature, vol. 544, no. 7649, pp. 227-230, 2017.
[21] A. S. Shaja and K. Sudhakar, "Motifs insights from engineering systems architectures," Complexity, vol. 18, no. 2, 52 pages, 2012.

[22] Q. Guan, H. An, N. Liu, F. An, and M. Jiang, "Information connections among multiple investors: evolutionary local patterns revealed by motifs," Scientific Reports, vol. 7, no. 1, article 14034, 2017.

[23] T. Ohnishi, H. Takayasu, and M. Takayasu, "Network motifs in an inter-firm network," Journal of Economic Interaction and Coordination, vol. 5, no. 2, pp. 171-180, 2010.

[24] J. Maluck, R. V. Donner, H. Takayasu, and M. Takayasu, "Motif formation and industry specific topologies in the Japanese business firm network," Journal of Statistical Mechanics: Theory and Experiment, vol. 2017, no. 5, article 053404, 2017.

[25] R. Milo, S. Itzkovitz, N. Kashtan et al., "Superfamilies of evolved and designed networks," Science, vol. 303, no. 5663, pp. 1538-1542, 2004.

[26] F. An, X. Gao, J. Guan, H. Li, and Q. Liu, "An evolution analysis of executive-based listed company relationships using complex networks," Physica A: Statistical Mechanics and its Applications, vol. 447, pp. 276-285, 2016.

[27] H. Li, W. Fang, H. An, and L. Yan, "The shareholding similarity of the shareholders of the worldwide listed energy companies based on a two-mode primitive network and a one-mode derivative holding-based network," Physica A: Statistical Mechanics and its Applications, vol. 415, pp. 525-532, 2014.

[28] H. J. Li, H. Z. An, J. C. Huang, X. Y. Gao, and Y. L. Shi, "Correlation of the holding behaviour of the holding-based network of Chinese fund management companies based on the node topological characteristics," Acta Physica Sinica, vol. 63, pp. 048901-048913, 2014.

[29] E. Dietzenbacher and U. Temurshoev, "Ownership relations in the presence of cross-shareholding," Journal of Economics, vol. 95, no. 3, pp. 189-212, 2008.

[30] Y. Yafeh and O. Yosha, "Large shareholders and banks: who monitors and how?," Economic Journal, vol. 113, no. 484, pp. 128-146, 2003.

[31] R. Morck, M. Nakamura, and A. Shivdasani, "Banks, ownership structure, and firm value in Japan," Journal of Business, vol. 73, no. 4, pp. 539-567, 2000.

[32] M. Salehi, H. R. Rabiee, and M. Jalili, "Motif structure and cooperation in real-world complex networks," Physica A: Statistical Mechanics and its Applications, vol. 389, no. 23, pp. 5521-5529, 2010.

[33] C. Y. Huang, C. T. Sun, C. Y. Cheng, and J. L. Hsieh, "Bridge and brick motifs in complex networks," Physica A: Statistical Mechanics and its Applications, vol. 377, no. 1, pp. 340-350, 2007.

[34] S. Wernicke and F. Rasche, "FANMOD: a tool for fast network motif detection," Bioinformatics, vol. 22, no. 9, pp. 1152-1153, 2006.

[35] T. Squartini and D. Garlaschelli, "Triadic motifs and dyadic self-organization in the World Trade Network," in Self-Organizing Systems: IWSOS 2012, Lecture Notes in Computer Science, F. A. Kuipers and P. E. Heegaard, Eds., no. article 7166pp. 24-35, Springer, Berlin, Heidelberg, 2012.

[36] J. Maluck and R. V. Donner, "A network of networks perspective on global trade," PLoS One, vol. 10, no. 7, article e0133310, 2015. 
[37] D. P. Ellerman, "Cross ownership of corporations: a new application of input-output theory," Metroeconomica, vol. 42, no. 1, pp. 33-46, 2010.

[38] S. Claessens, S. Djankov, and L. H. P. Lang, “The separation of ownership and control in East Asian Corporations," Journal of Financial Economics, vol. 58, no. 1-2, pp. 81-112, 2000.

[39] S. X. Li and R. Greenwood, "The effect of within-industry diversification on firm performance: synergy creation, multimarket contact and market structuration," Strategic Management Journal, vol. 25, no. 12, pp. 1131-1153, 2004.

[40] F. Turnovec, "Privatization, ownership structure and transparency: how to measure the true involvement of the state," European Journal of Political Economy, vol. 15, no. 4, pp. 605-618, 1999.

[41] F. Turnovec, "Arithmetics of property rights: a Leontief-type model of ownership structures," Homo Oeconomicus, vol. 22, no. 3, pp. 371-379, 2005.

[42] D. P. Ellerman, Intellectual Trespassing as a Way of Life: Essays 'in Philosophy, Economics, and Mathematics, Rowman \& Littlefield, 1995.

[43] H. Li, H. An, J. Huang, X. Huang, S. Mou, and Y. Shi, "The evolutionary stability of shareholders' co-holding behavior for China's listed energy companies based on associated maximal connected sub-graphs of derivative holding-based networks," Applied Energy, vol. 162, pp. 1601-1607, 2016. 


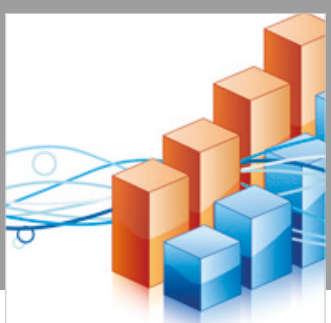

Advances in

Operations Research

\section{-n-m}
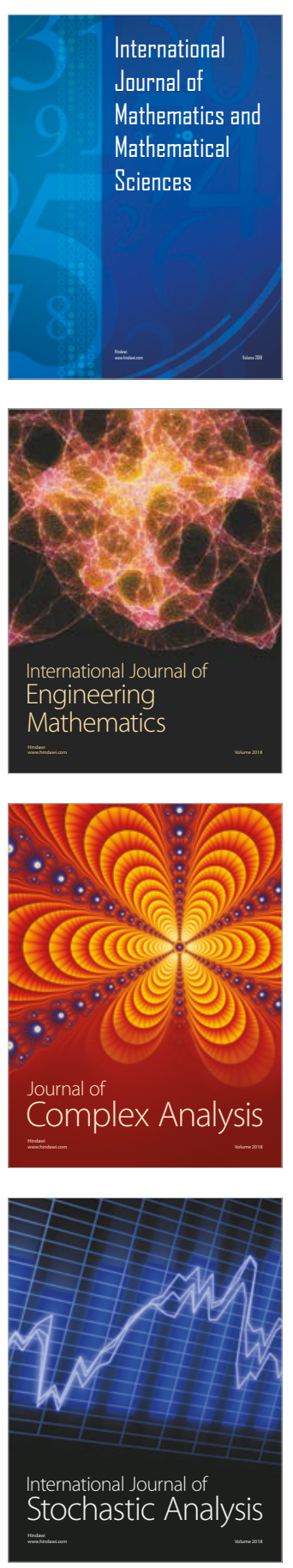
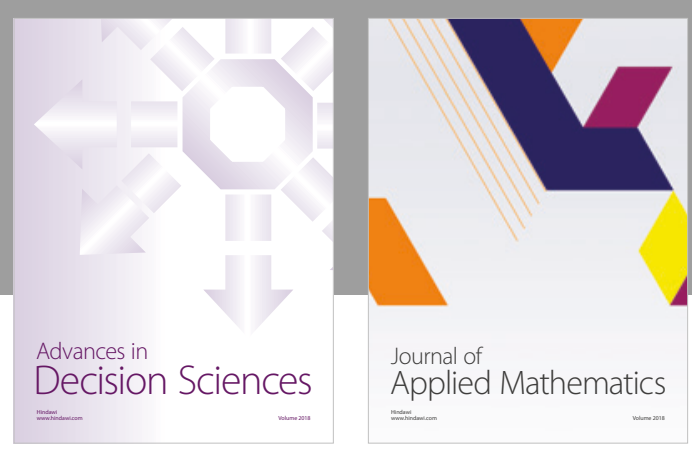

Journal of

Applied Mathematics
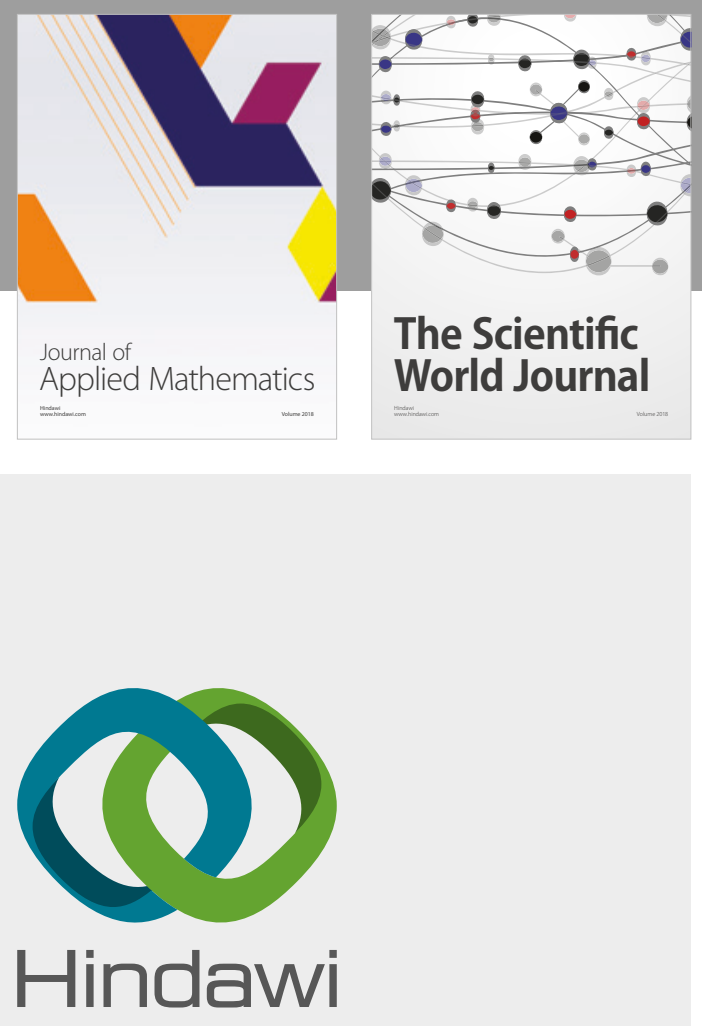

Submit your manuscripts at

www.hindawi.com

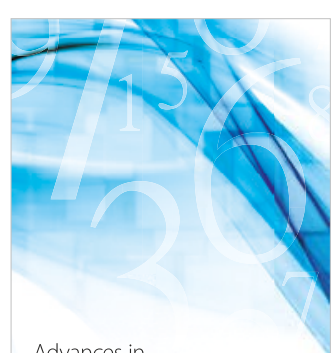

Advances in
Numerical Analysis
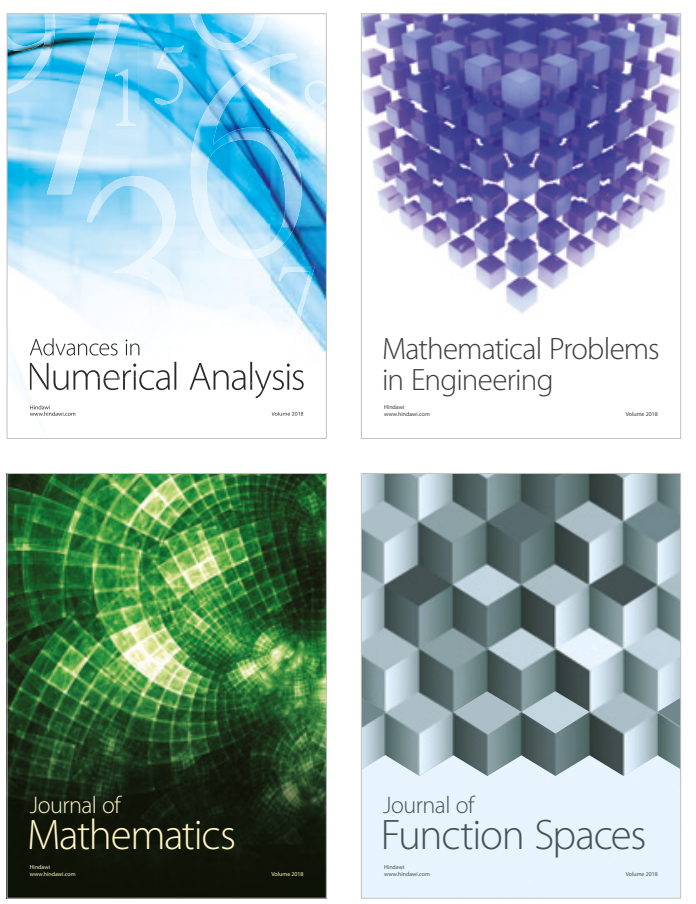

Mathematical Problems in Engineering

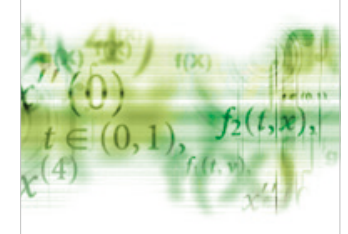

International Journal of

Differential Equations

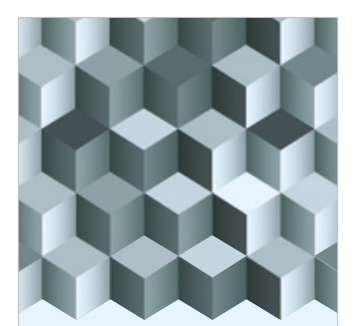

Journal of

Function Spaces
The Scientific

World Journal

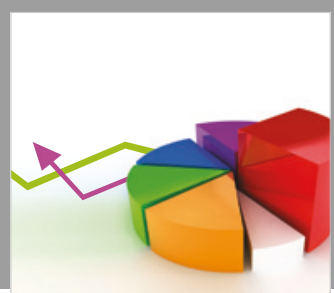

Journal of

Probability and Statistics
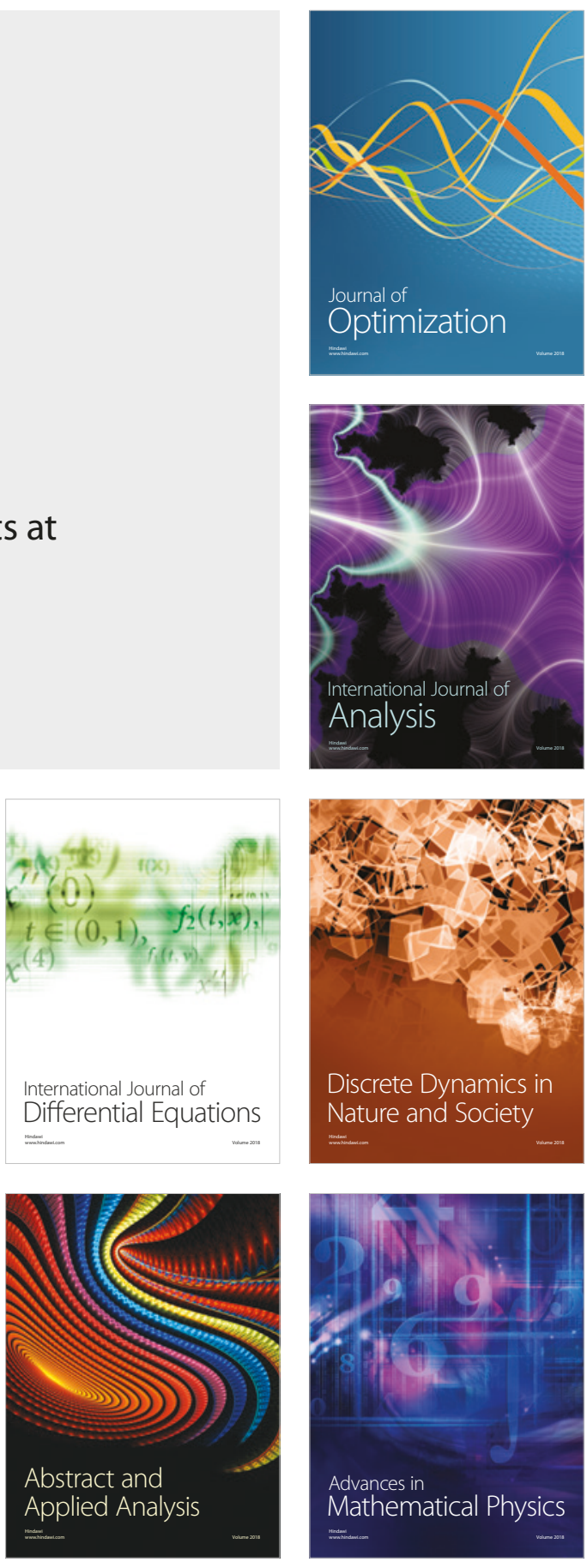